\title{
IPTEKS PENGAWASAN TERHADAP REALISASI ANGGARAN DENGAN KONSEP GOOD GOVERNANCE DALAM MENCEGAH PRAKTEK KORUPSI DI DINAS PEKERJAAN UMUM DAN PENATAAN RUANG DAERAH PROVINSI SULAWESI UTARA
}

\author{
Andre Feral Adolf Tombokan ${ }^{1}$, Sonny Pangerapan ${ }^{2}$ \\ ${ }^{1,2}$ Jurusan Akuntansi,Fakultas Ekonomi dan Bisnis Universitas Sam Ratulangi, Jl. Kampus Unsrat, Manado, \\ 95115, Indonesia \\ E-mail : andretombokan@gmail.com
}

\begin{abstract}
Indonesia's development depends on managing the budget state revenues and expenditures (APBN) therefore the government must be aware and change his character not to work alone without paying attention the interest or aspirations of the community. The purpose of this research is to know the flow or budget process at the public works agency and spatial planning in north Sulawesi province know the concept of good governance in carrying out supervision of realization budget, and to find out good governance in an effort to prevent corruption practices .this research is a qualitative research approach interpretive . the source of data from this study is primary data in the form of direct interviews, documentation and recording. Technique processing and analysis of data, namely the method of comparison by finding answers fundamental answers to cause and effect by analyzing factors the cause of the occurrence or emergence of a particular phenomenon. The result of this study indicate that the flow and budget process is on the PUPRD office in north Sulawesi, the budget planning process starts from conducting infestation field survey, after conducting surveys and data needed has been fulfilled, the budget calculation is carried out after it is entered planned DPA (budget implementation document) budget activities, after the DPA is published, we switch the process of physical implementation of work, including planning, design and so on, the concept of good governance in doing supervision of government budget realization is responsible for optimize the relationship between input and output. For example, for example public works agency, its input in the form of a budget can still be seen in its performance. Control,focused on how to utilize input minimum to produce the desired output that is in accordance with provisions and quality standards set at the time and quantity as which are desired.
\end{abstract}

Keywords : supervision of budget realization

\section{PENDAHULUAN}

Indonesia adalah ekonomi berbasis pasar, di mana pemerintah memiliki paling banyak peran penting. Pemberlakuan otonimi daerah mengakibatkan terjadinya perkembangan dan perbaikan sistem keuangan dan akuntansi di instansi pemerintah daerah agar sistem tata kelola yang lebih menonjol. Perubahan tersebut di tunjukan dengan adanya perkembangan peraturan yang telah di keluarkan oleh pemerintah pusat, seperti Undang-undang (UU) 17 Tahun 2003 tentang keuangan Negara, UU no. 32 dan 33 Tahun 2004 tentang Otonom daerah, serta beberapa undang-undang maupun aturan-aturan lain yang memang menjadi peraturan pengelolaan keuangan terhadap pemerintah pusat maupun daerah. Situasi ini akan member dorongan ke perkembangan pada bidang akuntansi menjadi lebih begitu ketat dan teliti.

Terjadinya masalah dalam keuangan saat ini sangat dapat kita rasakan hingga terjadi hambatan penerimaan Negara berakibat lemahnya ekonomi yang tak berkesudahan dan 
dampaknya yaitu penurunan pemberian serta pembiyayaan pekerjaan-pekerjaan kepemerintahan oleh pemerintah pusat. Maka dari itu untuk mengenali sumber kemampuan suatu daerah dan untuk membiyayai anggaran perbelanjaan daerah yang nyata, bertanggung jawab merupakan salah satu persyaratan ke tugas utama pemerintah,

\section{TINJAUAN PUSTAKA}

Sesuai dengan peraturan pemerintah nomor 71 tentang Standar Akuntansi

Pemerintahan (SAP). Komponen-komponen yang terdapat dalam suatu laporan keuangan yang berbentuk pencatatan yang terdiri dari laporan financial. Yang jika diuraikan sebagai berikut : LRA, LPS, LO, LPE, Neraca, LAK, dan Catatan Atas Laporan Keuangan.

Konsep Good Governance. Pemerintah yang baik (good governance) menurut LAN dan BPKP yaitu suatu masalah yang terpusat yang ketermuka dalam hal pengelolaan administrasi. Tuntutan yang sering masyarakat lakukan pada pemerintah untuk menyelenggarakan pemerintah yang baik yaitu berjalan dengan peningkatan pengetahuan dari masyarakat, selain adanya pengaruh dari globalisasi. Maka dari itu, ini merupakan tuntutan yang wajar yang seharusnya sudah di berikan pemerintah dengan melakukan perubahan yang terarah dengan terwujudnya penyelenggara pemerintah yang baik. Maka dari itu, good governance mempunyai tiga jaringan, yaitu state (Negara atau pemerintah), private sector (sector swasta atau dunia usaha), society (masyarakat), yang bersamaan menjalankan fungsinya masingmasing.

Praktek Korupsi. Menurut hasil dan survei dari Polotical dan Econimic Risk Consultancy (PERC) Hongkong dan Transpanrency Internasional Jerman mengenai tentang korupsi Indonesia sudah tidak asing lagi dengan kata dari korupsi ini. Tetapi sampai saat ini juga tidak ada penanganan yang serius mengenai kasus-kasus korupsi yang ada di Indonesian. Begitu juga dengan analisis masalah korupsi di Dinas Pekerjaan Umum dan Penataan Ruang Daerah Provinsi Sulawesi Utara, tentang pembangunan jalur khusus ambulance dari bahu ke rumah sakit malalayang sepanjang 2,2 km dan tentang pembangunan taman wisata serta pembangunan jalan menuju ke perumahan relokasi korban banjir tahun 2014 bahwa penulis mewawancarai salah satu pegawai di dinas PUPRD di mana kasus tersebut belum ada lanjutan dari pihak-pihak terkait dan enggan mengatakan bahwa dimana kasus tersebut terkait dengan korupsi.

\section{METODE DAN TEKNIK PENERAPAN}

\subsection{Metode Penerapan Ipteks}

Metode Ipteks yang digunakan adalah pengawasan aktiv dan pasif pengawasan aktiv di lakukan sebagai bentuk pengawasan yang di laksanakan di tempat kegiatan. pengawasan pasif merupakan pengawasan yang di lakukan melalui penelitian dan pengujian terhadap surat-surat,pertanggung jawaban,dan disertai dengan bukti penerimaan dan pengeluaran, dalam pengawasan terhadap anggaran.

\subsection{Teknik Penerapan Ipteks}

Teknik penerapan yang di gunakan yaitu pegawasan berdasarkan kebenaran fomil dan pengawasan berdasarkan kebenaran materil. Pengawasan berdasarkan kebenaran formil merupakan pengawasan yang di lakukan terhadap setiap pengeluaran apakah telah sesuai dengan peraturan yang berlaku . sedangkan pengawasan berdasarkan kebenaran materil merupakan pengawasn terhadap setiap pengeluaran apakah sudah sesuai dengan tujuan di keluarkan anggaran dan telah memenuhi prinsip ekonomi. 


\section{PEMBAHASAN}

\subsection{Gambaran Objek Penerapan Ipteks}

Dinas Pekerjaan Umum Prov. Sulawesi Utara merupakan salah satu Satuan Kerja Perangkat Daerah (SKPD) yang ada di Kota Manado yang bertugas untuk membantu Pemerintah dan Masyarakat dalam penyediaan jasa kontruksi prasarana dan sarana berdasarkan Peraturan Pemerintah No.24 Tahun 2005. Di mana suatu instansi akan berjalan dengan baik jika mempunyai pemimpin yang baik dalam sisi kepemimpinan. Pemerintah yang baik dalam penyelenggaraan pemerintah merupakan suatu upaya yang bersih dari korupsi. Dan untuk seluruh jajaran instansi pemerintah untuk melaporkan harta kekayaan, membuat penetapan kinerja, meningkatkan kualitas pelayanan masyarakat, mencegah kebocoran dan pemborosan barang dan jasa, memberikan dukungan upaya penindakan korupsi, menerapkan kesederhanaan serta penghematan. KPK dan Mentri Pendayagunaan Aperatur Negara RI Telah memberikan langka-langkah tentang pemerintahan yang baik yaitu peningkatan kapasitas, penerapan manajemen berbasis kinerja, pelayanan sektor publik, pencegahan korupsi pada pengadaan barang dan jasa, peningkatan kemampuan para pejabat, peningkatan kesadaran anti korupsi, penaganan pengaduan masyarakat.

\subsection{Pembahasan}

Berdasarkan hasil wawancara tentang proses pengawasan terhadap realisasi anggaran dalam pencegahan korupsi di Dinas PUPRD Provinsi Sulawesi Utara diketahui bahwa:

1. Setiap kertas tagihan bahkan pengeluaran yang ada di bagian keuangan akan di lengkapi dengan surat-surat yang sah.

2. Verifikasi tanda tangan kepala Dinas dan staf-staf yang bersangkutan.

3. Membuat daftar pembayaran dan surat permohonan pembayaran ke keuangan.

4. Posting sesuai No dokumen yang ada di daftar pembayaran oleh supervisor administrasi umum.

\section{KESIMPULAN DAN SARAN}

\subsection{Kesimpulan}

Di atas kita dapat menggunakan konsep good goverance untuk mengawasi praktek korupsi agar kepemerintahan atau instansi dapat mengetahui dan mencegah adanya praktek korupsi di instansi tersebut dan tentunya harus berpegangan pada Undang-Undang yang berlaku tentang penanggulan korupsi agar kepemerintahan di instansi tersebut bersih dari kasus korupsi.

\subsection{Saran}

Berdasarkan kesimpulan di atas, maka saran atas ipteks ini adalah bahwa dalam penyelenggaraan pengawasan praktek korupsi di Dinas PUPRD Prov. Sulut Pemerintah Pusat harus memiliki komitmen dalam mengawal dan mengawasi anggaran-anggaran yang disalurkan agar anggaran-anggaran tersebut dapat terealisasi dengan semestinya agar dapat terciptanya suatu instansi yang di dalamnya mempunyai kepemimpinan atau kepemerintahan yang baik sesuai dengan konsep Good Governance.

\section{DAFTAR PUSTAKA}

Abidin. 2002. Pengantar Administrasi Public, Modul untuk Matrikulasi Administrasi Public, MPA-UGM, Yogyakarta

Adwira., Muhammad ferdiansyha., Putusudana. 2015. Akuntabilitas, transparasi, dan anggaran berbasis kinerja pada satuan kerja perangkat daerah kota Denpasar. EJurnal akuntansi 11.2(2015):611-628. 
A, Zayyadi. 2018. Good Governance dalam Perspektif Hukum Islam Kontemporer. Purwokerto. Indonesia

Basalama, s. 2014. Perilaku organisasi memahami dan mengelola aspek humaniora dalam organisasi. Edisi 3.depok: usaha kami. Depok. Indonesia.

Cacaud, P. 2003 Administrasi Sanction in Fisheries Law. Journal FAO Legislative Study Of The United Nations .Rome

Deddy., Nordiawan.2006.Akuntansi Sector Public.salimba4.

Fitriani. 2012. Penerapan AHP sebagai Model System Pendukung Keputusan. Jurnal kebangsaan.5(2).12-45. Jakarta.

J, Zachawerus., A, Soekiman. 2018. Fakto-Faktor yang Mempengaruhi Kesuksesan Pelaksanaan Proyek Jalan Nasional di Maluku Utara. Maluku.

K, Teguh. Peranan Akuntanbilitas Publik dan Partisipasi Masyrakat dalam Pemberantasan Korupsi Pemerintahan. Bisnis dan Birokrasi. Jurnal Ilmu Administrasi dan Organisasi. Vol. 16 No. 2 2009. Fakultas Ilmu Sosial dan Politik. Universitas Indonesia. Jakarta

Mardiasmo. 2002. Akuntansi Sector Public. Penerbit andi .Yogyakarta

Manggopa, Megi wawancara. 2018. Wawancara mengenai Pengawasan Realisasi Anggaran Pencegahan Korupsi.J1.Ttikala Ares

T, Darmi. 2006. Penerapan Prinsip Good Governance untuk Layanan Publik. Universitas Muhammadiya. Palu. Indonesia 